[DOI: 10.24214/jecet.A.9.4.64451.]

Jaurnal of Environmental Science, Computer Science and Engineering \& Technology

An International Peer Review E-3 Journal of Sciences and Technology

Available online at www.jecet.org

Section A: Environmental Science

Research Article

\title{
Climate and Human Health: Connecting Sequence of Actions
}

\author{
Shashikant Patel ${ }^{1}$, Janak P Joshi ${ }^{2}$ and Bindu Bhatt ${ }^{3}$ \\ ${ }^{1}$ Scientist (Geology, Water Resources, Geo-informatics \& IT- Division) Punjab \\ Remote Sensing Centre (PRSC), PAU-Campus, Ludhiana, Punjab-141004 \\ ${ }^{2}$ GIS Specialist, Smart City Project, Vadodara \\ ${ }^{3}$ Department of Geography, Faculty of Science, the Maharaja Sayajirao University of \\ Baroda, Vadodara
}

Received: 17 September 2020; Revised: 2 October 2020; Accepted: 10 October 2020

\begin{abstract}
Climatic conditions affect human well-being both directly through climatic extremes, and indirectly, through the levels of pollution in the air, agriculture, water systems that provide food and water, and on the vectors and pathogens that cause infectious diseases. It is now accepted that human beings are influencing the global climate, hence, the decision-makers are now concentrating on the nature and time of actions to limit the rate of change. The health sector is essential to achieving sustainable development; it plays a fundamental role in protecting human health from the impacts of climate change as outlined in Millennium Development Goals (MDGs) and Sustainable Development Goals (SDGs). Concentration is shifting to the balance between the probable impacts of climate change, and the economic costs, technological advances, and societal adaptations that are necessary for mitigation. The attempt here is to arrange sequences of actions, a journey through time by connecting a climate and human health
\end{abstract}

Key Words: Climate, Health, History, Millennium Development Goals 


\section{INTRODUCTION}

Health is influenced by climate and weather in many ways, and for several reasons, it is difficult to anticipate all the impacts. Before the prospect of anthropogenic climate change emerged, epidemiologists were not greatly interested in climate-health relations. An assessment by WHO in 2004 concluded that approximately 166,000 deaths had occurred in the year 2000 due to the climate change that had occurred between 1990 and 2000. Between 2030 and 2050, climate change is expected to generate nearly 300,000 additional deaths per year, increasing child malnutrition and undernutrition, insect-borne diseases, diarrhea, and heat-related stresses

The Intergovernmental Panel on Climate Change (IPCC) ${ }^{[1]}$ divides the impacts of climate change on health into three pathways: direct impacts, indirect impacts through natural systems, and indirect impacts through socioeconomic systems. However, health outcomes are not necessarily derived directly from those drivers. The social determinants of health (both individual and collective) and the presence and quality of health systems may modulate, for better or worse, the final health outcomes of those changes. Climate change operates at many levels and its influence on health outcomes varies both in time and space. In general, it plays a multiplier role, typically amplifying or extending a population's pre-existing health risks or problems. Although the impacts and consequences of climate change are likely to be many and complex, climate change is already affecting human health and wellbeing

The Fourth Assessment Report (AR4) pointed to the dramatic improvement in life expectancy in most parts of the world in the 20th century, and this trend has continued through the first decade of the 21st century. ${ }^{[2]}$ Rapid economic advancement in some countries has benefited, but most countries have an advantage from significant reductions in mortality. There remain sizable and avoidable inequalities in life expectancy within and between nations in terms of education, income, and ethnicity ${ }^{[3]}$ and some countries, official statistics are so patchy in quality and coverage that it is difficult to draw firm conclusions about health trends. ${ }^{[4]}$ Years lived with disability have tended to increase in most countries ${ }^{[5]}$. To prevent the further change of the global climate the emissions of greenhouse gases must be significantly reduced (= mitigation). At the same time policies and programs to reduce the impacts of unavoidable climate change (= adaptation), are needed to protect the human population from the inevitable exposures to ongoing climate change.

\section{CLIMATE AND HUMAN HEALTH}

An ancient struggle: The history of the world portrays the examples of the impact of infectious diseases on populations, for example, a 3000-year-old Egyptian mummies support the presence of smallpox.

Nevertheless, human health and disease are possibly related to climate are found as historical records. The Greek physician Hippocrates (about 400 BC) related epidemics to seasonal weather changes, writing that physicians should have "due regard to the seasons of the year, and the diseases which they produce, and to the states of the wind peculiar to each country and the qualities of its waters" [6] He exhorts them to take note of "the waters which people use, whether they be marshy and soft, or hard and running from elevated and rocky situations, and then if saltish and unfit for cooking," and to observe "the localities of towns, and the surrounding country, whether they are low or high, hot or cold, wet or dry and of the diet and regimen of the inhabitants".

According to Hippocrates: "Whoever wishes to investigate medicine properly, should proceed thus: in the first place to consider the seasons of the year, and what effects each of them produces, for they are 
not all alike, but differ much from themselves in regard to their changes." As there was development and advances in modern scientific knowledge, perceptive that human health can be affected by a wide variety of environmental interference, following climate change was acknowledged

Robert Plot Secretary to the newly-founded Royal Society in England, a two thousand years later, based on weather observations, in 1683-84 was of opinion that if the same observations were made "in many foreign and remote parts at the same time" we would "probably in time thereby learn to be forewarned certainly of divers emergencies (such as heats, colds, deaths, plagues, and other epidemical distempers).

In course of history, numerous climatic calamities were experienced by communities and populations, more or less in all the parts of the world. This seems to have resulted in hunger, communicable disease, social collapse, and the vanishing of entire populations. There are records of many episodes of acute famine as a reaction to climatic fluctuations.

Fracastoro presented the germ theory in the 1500s and three routes of contagion were proposeddirect contact, fomites, and contagion from a distance (airborne). The large-scale occurrence of infectious diseases like leprosy, plague, syphilis, smallpox, cholera, yellow fever, typhoid fever, and others was frequent. Consequently, ever since olden times, human health has constantly been susceptible to plague, famine, injury, and problems of childbirth.

The development of the microscope by Leeuwenhoek in the 1600s helped scientists to visualize microorganisms for the first time. The $1800 \mathrm{~s}$ brought familiarity with the cultivation and identification of microorganisms. Vaccines were developed and used with an established definite technique for the control and prevention of many communicable diseases. Pasteurization also added to disease control.

A relationship between the environment and infectious diseases was recognized, a wide range of control measures such as community sanitation, personal hygiene, and public health education has been introduced. At the same, the importance of a healthy diet was equally important to control infectious diseases.

As the man was able to manage these conditions and there was an increase in life expectancy, a whole new range of non-communicable diseases NCDs or lifestyle evils like diabetes, hypertension, cardiovascular, respiratory, and kidney diseases, and mental health issues became more common.

Diseases like hemorrhagic fevers, Nipah virus, and monkey-pox, etc., are a matter of global concern although they are geographically confined small areas. Besides, more recently sudden acute respiratory syndrome (SARS), Middle East Respiratory Syndrome (MERS), EBOLA, and now COVID 19, the occurrence of a new and hazardous infectious disease that bothers governments, causes terror and panic among people; have a major impact on the economy of the countries worldwide and the movement of people. Much attention has been given to the vector-borne and infectious disease risks related to climate change [7]. NCDs are not as obviously associated with climate change as are fires, floods, famines, changes in the distribution of existing infectious diseases, and the emergence of new microbial infections. However, there will also be various impacts on noncommunicable diseases (NCDs). ${ }^{[8]}$

As health is of individual wellbeing but the viral disease is creating another dimension of the community wellbeing. As historically, it has been observed that the sudden outbreaks of the viral disease have always posed a challenge to the health care to device a line of the treatment, to accommodate the patients along with the containment of the disease and the economic burden. May it be the 1918's Spanish flu (H1N1); 2009's Swine flu (H1N1); 2020's: COVID-19 these diseases 
outbreak has proved that still environment has several unexplored disease-causing virus/bacteria and we have a long battle to conquer in the race of development? The epidemic and pandemics have a huge impact on paralyzing the economy and health care system with the unprecedented service demand.

Thus, an essential requirement of the development is to keep nature in the harmony with Community participation is key to successfully controlling outbreaks.

Beginning of the new Era: In the years later, WHO (World Health Organization) published its first brief assessment of climate change health impacts in 1989 followed by a substantial review in $1996^{[9]}$ and many other reports later. For instance, an attempt to estimate the global burden of disease and injury due to the climate change that had occurred between 1990 and 2000 was supported by WHO. The Kobe Centre of WHO coordinated a Knowledge Network on Social Determinants of Health in Urban Settings that discussed climate change effects on health equity.

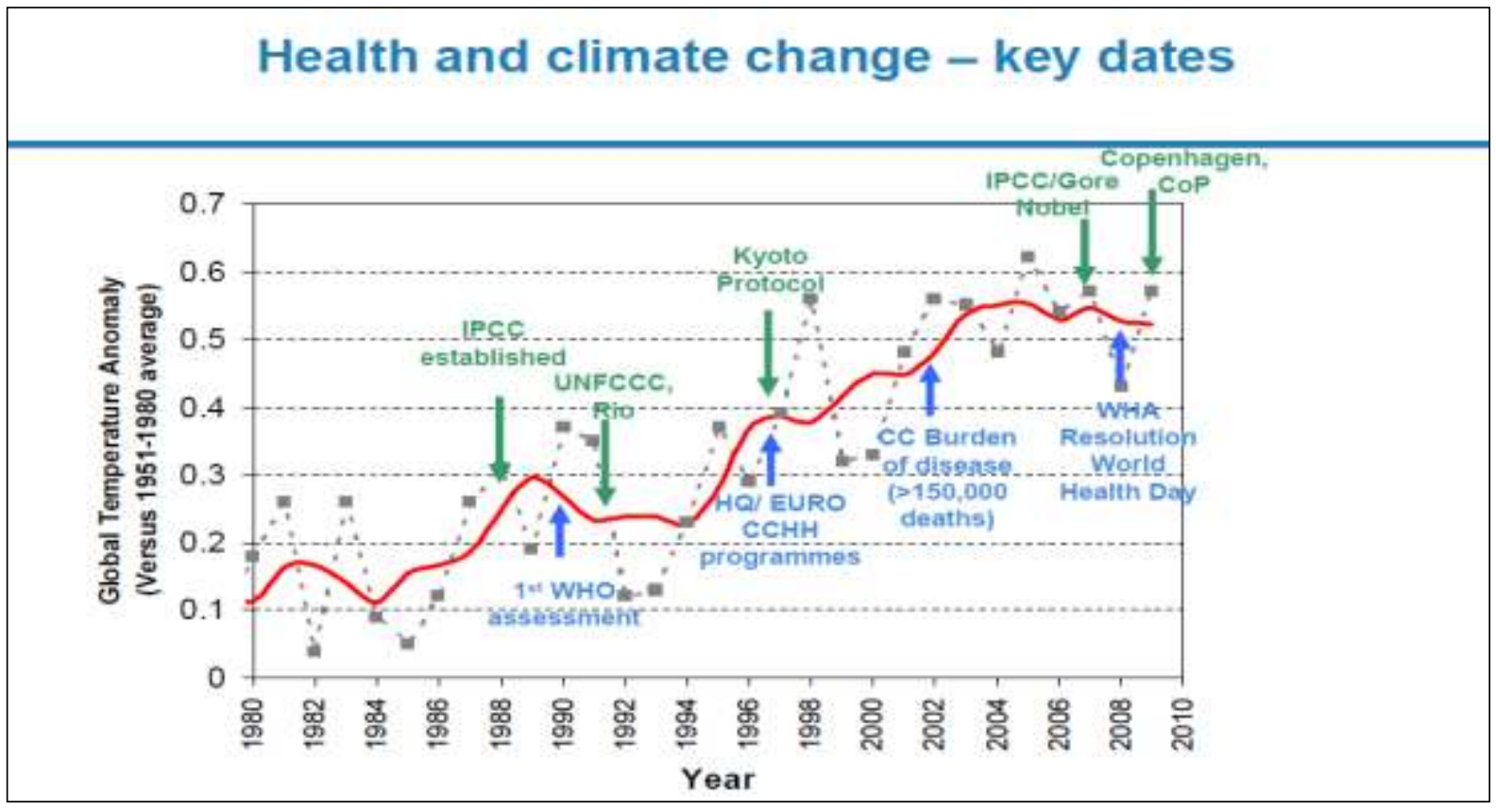

Fig.1: Health and climate change key dates

[ Source:http://www.who.int/globalchange/climate Health and Climate Change -Past, Present, Future Dr. Maria Neira, Director Public Health and Environment Department World Health Organization Geneva]

A resolution on Climate Change and Health was adopted at the 2008 World Health Assembly (WHA61.19), to draw the attention of the community and policy-makers on possible impacts of climate change on global health security and on the efforts to achieve the health-related Millennium Development Goals. In response; the theme of 2008 World Health Day was "Protecting Health from Climate Change". ${ }^{[10]}$

The WHO resolution also requested the Director-General "to consult with the Member States on the preparation of a work-plan for scaling up technical support to the Member States for assessing and addressing the implications of climate change for health and health systems. 
The world is experiencing a triple catastrophe of chronic, non-communicable diseases (NCDs), economic, geopolitical instability, and climatic threat. The magnitude of these crises is unprecedented with both climate change ${ }^{[10]}$ and NCDs ${ }^{[11]}$ described as among the 21 st Century's challenges. The magnitude of the global impact of NCDs is such that, in 2011, The UN General Assembly held its second only special meeting dedicated to a specific disease area on NCDs - the first being on HIV/AIDS 10 years earlier. Shortly thereafter, the UN Rio+20 Conference on Sustainable Development published its Outcomes Document, The Future We Want which recognizes health as: " $a$ precondition for and an outcome and indicator of all three dimensions of sustainable development...." the three dimensions being environmental, social, and economic.

The Rio+20 Outcomes Document also specifically cites NCDs as a threat to sustainable development. Given this, it is surprising that the links between climate change and NCDs have received relatively little attention to date. However, there is a sizeable and growing literature on climate change and health more broadly. For example, the notion of 'one planet-one health' holds that human, animal, and planetary health are so inextricably interlinked that the well-being of each is dependent on the wellbeing of the other ${ }^{[12,13] .}$

In general, the range of possible impacts on NCDs has received little attention. NCDs will likely be affected by climate change in two ways. First, climate change itself may, directly and indirectly, increase the incidence of NCDs. Second, policy responses to climate change-both adaptation and mitigation-will likely have both positive and negative implications for NCDs.

\section{WAY AHEAD}

Adaptation and Climate-Resilient Health Systems: Climate change threatens human health, but may be considered a challenge and a strong argument for a transition to more sustainable and healthy societies with "climate-resilient" health systems ${ }^{[14]}$. The efforts of countries to achieve key sustainable development goals (SDGs) under the 2030 Agenda for Sustainable Development are threatened by climate change (e.g., SDG 1 -No poverty; SDG 2-End hunger; SDG3 - Good health and well-being; and SDG 6 - Clean water and sanitation) ${ }^{[15] .}$

Health authorities and researchers, from international to local levels, recognize the serious threats to health, that climate change poses and are taking protective measures to reduce current impacts

And future risks ${ }^{[16]}$. Evidence-based information about current and possible future risks to health, vulnerable populations, and effective adaptation options is needed to prepare individuals and communities for the health impacts of climate change ${ }^{[17,18]}$. This includes identification of innovative adaptations for use by public health officials to understand and respond to more severe and possibly compounding effects of future climate change, such as threats from tipping points and shock events that are outside of the range of current experience ${ }^{[19] .}$

Adaptation is indispensable both to tackle the burden of disease because of climate change and support public health and health services. Building a climate-resilient society takes into account climate change by suitable public health and health service interventions, such as education, vaccination, vector control, food and water sanitation and hygiene assessment of the surrounding, nutrition, mental health care, disease surveillance, and disaster awareness.

The adaptation is not only the human habits rather it also requires the practices to minimize the contaminants of the natural resources. The agriculture practices are essentially required to increase yield along with reducing the chemical used footprints. The transport connectivity is to increase to achieve MDG but has to be reducing the carbon footprint. 
Life expectancy is to increase with quality of the life, to have healthy demography participating in the development of the region and the nation. The Air, Water, land resources are contaminated to the extent that globally, around 7 Million people death per year are only attributed to air contaminant impact along with relatively high suffering with disease stroke, heart disease, lung cancer, COPD, Pneumonia. Thus reducing the contamination requires a shift in the practices to eco-friendly adaptation. Some of the adaptation can be primitive to the most technologically developed solution.

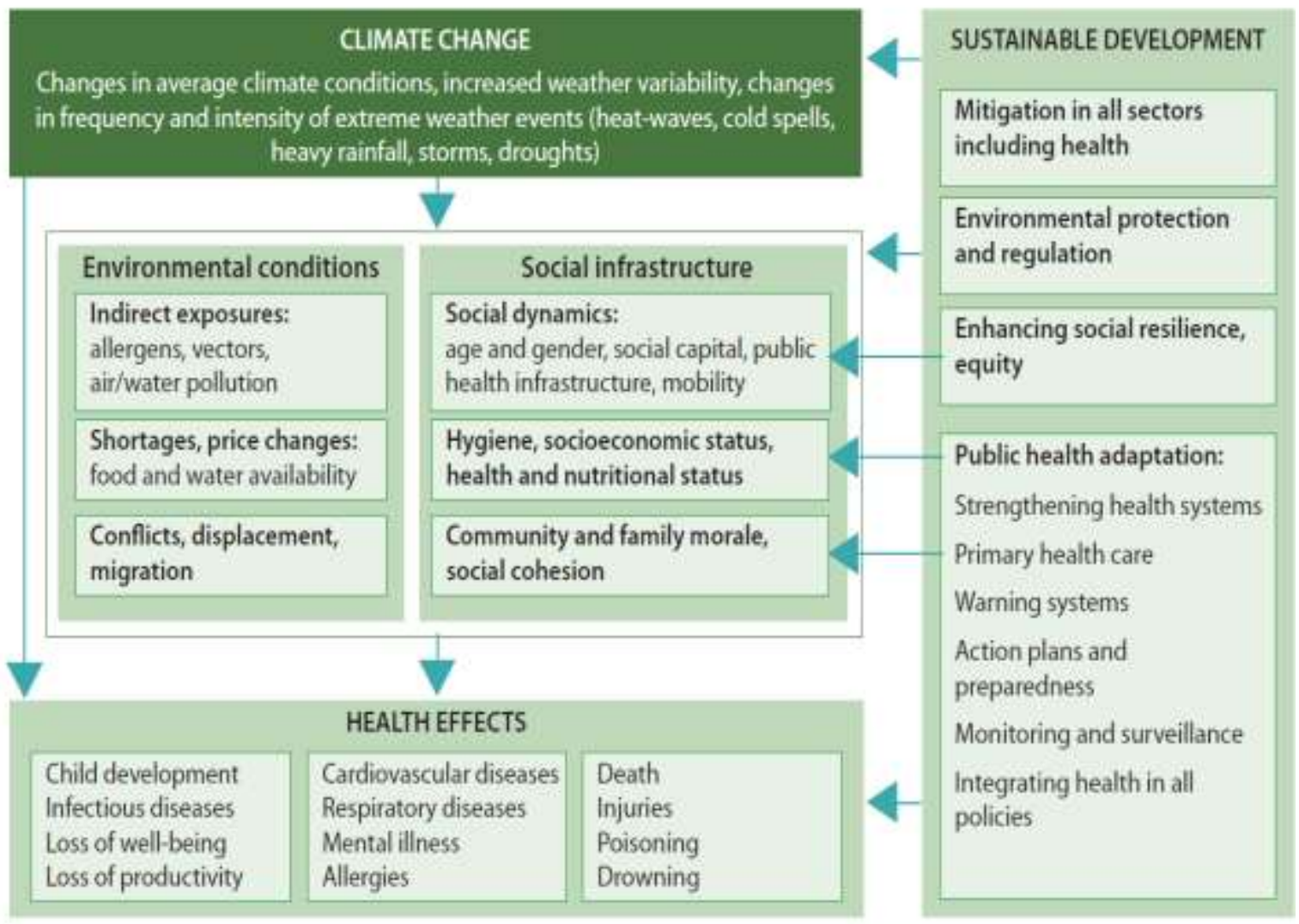

Fig.2: Climate change and health effect

Source: World Health Organization (WHO); Regional Office for Europe. Protecting Health from Climate Change in Europe: 2017 Update. Copenhagen, 2017. Available online: http://www.euro.who.int

Many of the health impacts of climate variability and change can be lessened or avoided through welldesigned adaptation measures ${ }^{[20] .}$ Health adaptation refers to "the process of designing, implementing, monitoring, and evaluating strategies, policies, and measures intended to reduce climate changerelated impacts and to take advantage of opportunities" [21]

The evidence implies that there is a very high benefit-cost ratio for health adaptation and that higher benefits are achieved with early adaptation action. Urban planning and sustainable transport approach can support health, reduce pollution to deal with climate change, and make cities more inclusive and sustainable. The action of climate change can improve health. This can be done using several actions like reducing air pollution, physical activity, and food habits. The health benefits resulting from such measures can help to address existing global health issues, such as mortality from cardiovascular and 
respiratory diseases, obesity, diabetes, and other non-communicable diseases. ${ }^{[22]}$ Government initiatives can bring in climate change, the green economy, and health as a national priority.

\section{CONCLUSION}

Climate change will make it more complex to control a wide range of climate-sensitive health effects. Therefore, to maintain and recover current levels of population health, it will be essential to continue to reinforce vital functions of health systems, the risks created by a changing climate, and to alter current health risk management activities to respond. The Informed social and community interaction, active participation will be the game-changer in the governance. Policies and plans will be required to go beyond present contemporary vulnerabilities, to protect against health risks from potential and perhaps more harsh climate change.

\section{REFERENCES}

1. K.R.Smith, A.Woodward, D.Campbell-Lendrum, D. D. Chadee, Y. Honda, Q.Liu, et al. Human health: impacts, adaptation, and co-benefits. 2014 In Climate change 2014: impacts, adaptation, and vulnerability. Part A: global and sectoral aspects. New York: Cambridge University Press: 709-754.

2. H.L.Wang, K.T. Dwyer-Lindgren, J.K. Lofgren, J.R. Rajaratnam, A. Marcus, C.E. Levin Rector, Levitz, A. Lopez, and C.J.L. Murray, Age-specific and sex specific mortality in 187 countries, 1970-2010: a systematic analysis for the Global Burden of Disease Study 2010. Lancet, 2012, 380, 2071-2094.

3. R.Beaglehole and R. Bonita, 2008: Global public health: a scorecard. Lancet, 2008, 372(9654), 1988-1996.

4. P. Byass, The imperfect world of global health estimates. PLoS Medicine, 2010, 7(11), e1001006, doi:10.1371/journal.pmed.1001006

5. J.A.Salomon, H. Wang, M.K. Freeman, T. Vos, A.D. Flaxman, A.D. Lopez, and C.J. Murray, Healthy life expectancy for 187 countries, 1990-2010: a systematic analysis for the Global Burden Disease Study 2010. Lancet, 2012, 380(9859), 2144-2162.

6. Hippocrates, Airs, Waters, and places. An essay on the influence of climate, water supply and situation on health. In Lloyd, G.E.R., ed., Hippocratic Writings. London, Penguin, 1978,p. 148.

7. A.Costello, M. Abbas, A.Allen, S.Ball, S. Bell, R. Bellamy, et al.; Managing the health effects of climate change: Lancet-University College London Institute for Global Health Commission. Lancet 2009; 373: 1693_733

8. T. Kjellstrom, A.J.Butler, R. Lucas, R. Bonita, Public health impact of global heating due to climate change _ potential effects on chronic non-communicable diseases. Int J Public Health 2010; 55: 97_103

9. A.J.McMichael, A. Haines, R. Slooff \& S. Kovats, Climate Change and Human Health. Geneva: World Health Organization,1996,

10. K.M.Ban, Ban Ki-Moon's Speeches: Opening Remarks at 2014 Climate Summit. http://www.un.org/apps/news/infocus/sgspeeches/statments_full.asp?statID=2355\#.VVW XllJBCuJ (accessed on 10, Apri, 2020). 
11. United Nations. The Future We Want: Outcome Document Adopted at Rio+20; United Nations: New York, NY, USA, 2013.

12. E.P.Gibbs, The evolution of one health: A decade of progress and challenges for the future. Vet. Rec. 2014, 174, 85-91.

13. B. Marais, J. Crawford, J. Iredell, M. Ward, S. Simpson, L. Gilbert, P. Griffiths, A. KamradtScott, R. Colagiuri, C. Jones, et al. One world, one health: Beyond the Millennium Development Goals. Lancet 2012, 380, 805-806

14. Tanja Wolf Katrina LyneGerardo Sanchez Martinez Vladimir Kendrovski The Health Effects of Climate Change in the WHO European Region, Climate 2015, 3, 901-936

15. United Nations Development Program (UNDP). Sustainable Development Goals. 2018. Available online: http://www.undp.org/content/undp/en/home/sustainable-developmentgoals.html.

16. G. Luber, J. Lemery, J. (Eds.) Climate change and health vulnerability assessments. In Global Climate Change and Human Health: From Science to Practice; Jossey-Bass: San Francisco, CA, USA, 2015.

17. World Health Organization and Pan American Health Organization. Protecting Health from Climate Change: Vulnerability and Adaptation Assessment. World Health Organization, 2013. Available online:http://www.who.int/iris/handle/10665/104200

18. World Health Organization (WHO). Operational Framework for Building Climate Resilient Health Systems. World Health Organization, 2015

19. K.L.Ebi, P. Berry, C. Boyer, K. Hayes, P.M. Enright, S. Sellers, J.J.S.; Hess, Stress testing the capacity of health systems to manage climate change-related shocks and stresses. Int. J. Environ. Res. Public Health 2018, 15, 2370.

20. H.Wang, L. Dwyer-Lindgren, K.T. Lofgren, J.K. Rajaratnam, J.R. Marcus, A. LevinRector, C.E. Levitz, A. Lopez, and C.J.L. Murray, Age-specific and sex specific mortality in 187 countries, 1970-2010: a systematic analysis for the Global Burden of Disease Study 2010. Lancet,2012, 380, 2071-2094.

21. 21.K.L. Ebi, J.C.Semenza, Community-based adaptation to the health impacts of climate change. Am. J. Prev. Med. 2008; 35:501-507. doi: 10.1016/j.amepre.2008.08.018.

22. A.Haines, A.J.McMichael, K.R.Smith, I. Roberts, J. Woodcock, A.Markandya et al. Public health benefits of strategies to reduce greenhouse-gas emissions: overview and implications for policy makers. Lancet. 2009;374(9707):2104-2114.

\section{Corresponding author: Bindu Bhatt.}

Department of Geography, Faculty of Science, The Maharaja Sayajirao University of Baroda, Vadodara; bindoobhatt@gmail.com

Date of publication on line 10.10.2020 